\title{
POWER SYSTEM STABILIZATION BY FUZZY SET THEORY BASED CONTROL OF SMES
}

\author{
Md. Rafiqul Islam Sheikh ${ }^{1}$, Rion Takahashi ${ }^{2}$, and Junji Tamura ${ }^{2}$ \\ ${ }^{1}$ EEE Department, Rajshahi University of Engineering \& Technology, Rajshahi 6204, Bangladesh \\ ${ }^{2}$ EEE Department, Kitami Institute of Technology, 165 Koen-cho, Hokkaido, Kitami, Japan \\ *Email: ris_ruet@yahoo.com
}

\begin{abstract}
At present fuzzy logic control is receiving increasing emphasis in process control applications. The paper describes the application of fuzzy logic control in a power system that uses a 12pulse bridge converter associated with Superconductive Magnetic Energy Storage (SMES) unit. The fuzzy control is used in both the frequency and voltage control loops, replacing the conventional control method. The control algorithms have been developed in detail and simulation results are presented. These results clearly indicate the superior performance of fuzzy control during the dynamic period of energy transfer between the power system and SMES unit.
\end{abstract}

Keywords: Fuzzy logic controller, power system dynamic performance, and SMES unit.

\section{Introduction}

Power system oscillations occur when there are system disturbances such as sudden loadchanges or faults. The damping of the system must be such that the synchronous generators can return to their steady state conditions after the disturbances [1]. Especially when the loadend of the transmission line experiences sudden load perturbations, the generators need continuous control to suppress undesirable oscillations in the system. Many countermeasures have been suggested by the researchers to increase the damping. These include power system stabilizers [2-3], optimal control of the turbine-governor system [4-6], and the use of static phase shifters [7-8].

Since the successful commissioning test of the BPA 30 MJ unit [9], SMES systems have received much attention in power system applications. Although the original purpose of the SMES unit is load leveling, an additional function of the SMES unit is the improvement of the system performance, by providing appropriate power modulation [10] during the dynamic period. The SMES can be applied for both active and reactive power compensation at suitable locations of the transmission line for both static and dynamic voltage control and system stability preservation [11-12]. However, some issues associated with the use of SMES unit still remain to be resolved. Two of these issues are, (i) the effective use of P-Q modulation, (ii) the evaluation of their performance after sudden disturbance.

One way to address these issues is to investigate the use of alternative control techniques. At present, the use of fuzzy logic is finding much application in several areas [1314]. In this study, the conventional SMES controller proposed is replaced by a rule based fuzzy controller. To demonstrate the effectiveness of the proposed fuzzy controller, its performance is compared with the conventional one. The results show that the SMES unit responds very quickly following a sudden load change due to the effective use of its P-Q modulation capability. Thus, the paper begins by outlining the main problems associated with conventional control scheme and then describes the details of the proposed fuzzy logic control scheme. The controller is applied to a test network and the simulation results are presented and discussed.

\section{Problems Associated with the Use of Conventional Control \\ 2.1. Review of Control Strategy}

Fig. 1 shows a typical configuration of a single area power system model equipped with a SMES unit. Application of a sudden load results in load-voltage and frequency deviations. Following these variations, the SMES unit is used to improve the performance subject to its limitation. The input to the SMES unit is a d.c voltage $\mathrm{V}_{\mathrm{sm}}$. This voltage is continuously varied by a 12-pulse cascaded 
bridge type ac/dc converter as shown in Fig. 2 . The converter d.c output current $\mathrm{I}_{\mathrm{sm}}$ being unidirectional, the control for the direction and magnitude of the inductor power flow $\mathrm{P}_{\mathrm{sm}}$, is achieved by continuously regulating the firing angle $\alpha$, under equal- $\alpha$ mode, which enables the $\mathrm{DC}$ voltage applied $\left(\mathrm{V}_{\mathrm{sm}}\right)$ to the inductor to be varied through a wide range of positive and negative values as shown in Fig. 3. The controller is shown in Fig. 4. A switched capacitor bank is also placed at the load end to provide additional Var as required for reactive power compensation. The control procedure described in detail can be summarized as follows:

(i) At first the required inductor voltage $V_{s m}$ is calculated by using the equation

$\mathrm{V}_{\mathrm{sm}}=\mathrm{K}_{0} \Delta \mathrm{f}-\mathrm{K}_{\mathrm{sm}} \Delta \mathrm{I}_{\mathrm{sm}}$

$\mathrm{P}_{\mathrm{sm}}=\mathrm{V}_{\mathrm{sm}} \mathrm{I}_{\mathrm{sm}}$,

where $\mathrm{K}_{0}$ and $\mathrm{K}_{\mathrm{sm}}$ are the gains corresponding to the frequency variation $(\Delta \mathrm{f})$ and the inductor current variation $\left(\Delta \mathrm{I}_{\mathrm{sm}}\right)$ respectively.

(ii) The desired reactive power $\mathrm{Q}_{\mathrm{dem}}$ can be calculated as

$\mathrm{Q}_{\mathrm{dem}}=\mathrm{K}_{\mathrm{v}} \Delta \mathrm{V}_{\mathrm{L}}$

and $\mathrm{Q}_{\mathrm{dem}}=\mathrm{Q}_{\mathrm{sm}}+\mathrm{Q}_{\mathrm{c}}$

where $\mathrm{Q}_{\mathrm{sm}}$ is reactive power provided by the SMES unit and $Q_{c}$ is the reactive power supplied by the switched capacitor; $\mathrm{K}_{\mathrm{v}}$ is the gain corresponding to load voltage deviation.

(iii)The SMES unit provides $\mathrm{P}_{\mathrm{sm}}$ and $\mathrm{Q}_{\mathrm{sm}}$ to improve the system performance by controlling the firing angles of the 12-pulse converter.

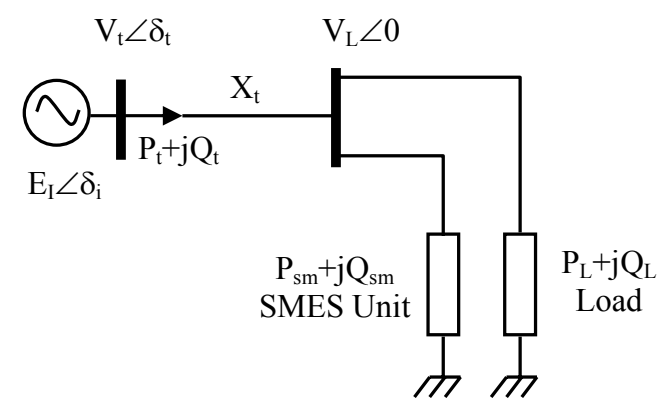

Fig. 1. Single line diagram for test network

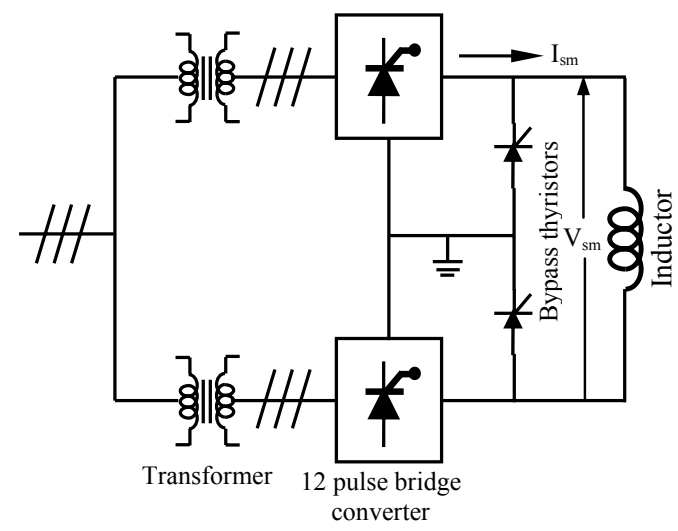

Fig. 2. SMES unit with 12-pulse bridge AC/DC thyristor controlled converter

\subsection{Problems Arising from the Conventional Control Strategy}

The use of $\Delta \mathrm{f}$ (error) signal alone is insufficient to determine the desired value of real power $\left(\mathrm{P}_{\mathrm{sm}}\right)$ modulation required by the SMES unit. In addition to this error signal, the change in error between successive samples should be used to determine $\mathrm{P}_{\mathrm{sm}}$. The absence of this additional signal makes the SMES unit less sensitive to the disturbance. This will in turn result in a larger value of $\Delta \mathrm{I}_{\mathrm{sm}}$ in the SMES unit. A similar problem arises when only load voltage deviation $\left(\Delta \mathrm{V}_{\mathrm{L}}\right)$ is considered to determine the desired value of reactive power modulation $\mathrm{Q}_{\mathrm{sm}}$, instead of the change in $\Delta \mathrm{V}_{\mathrm{L}}$ between successive samples.

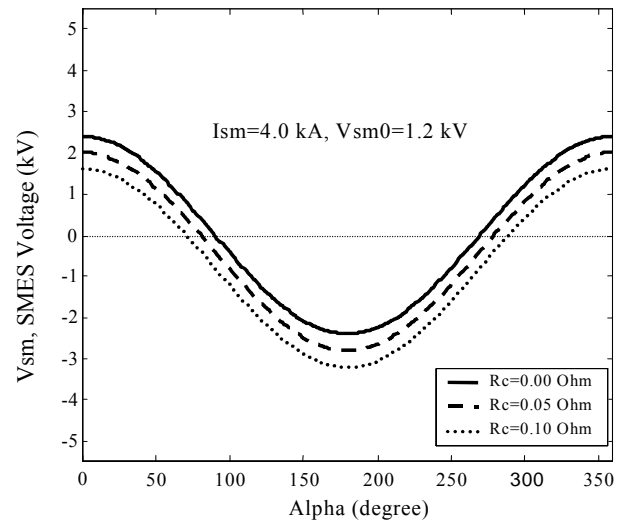

Fig. 3. Effect of inductor voltage, $\mathrm{V}_{\mathrm{sm}}$ with the variation of firing angle of 12-pulse converter 


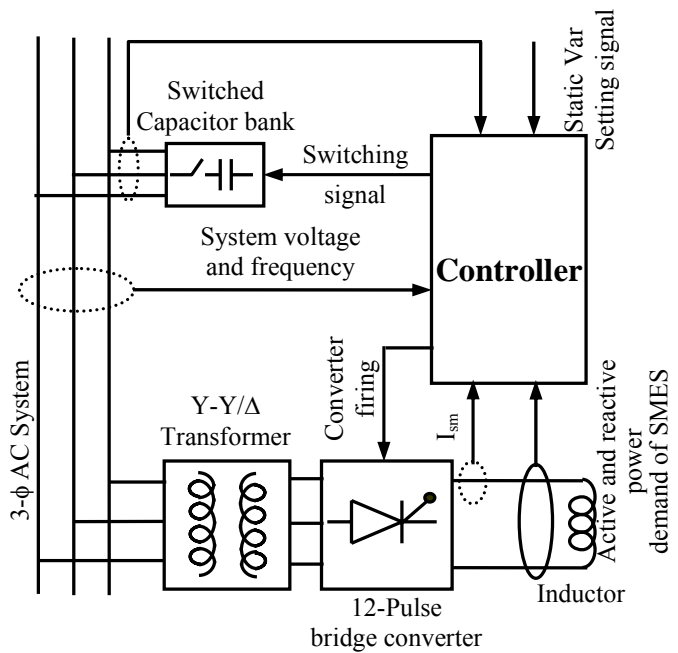

Fig. 4. The schematic diagram of the conventional control scheme

\section{Design of Proposed Fuzzy Logic Controller (FLC)}

Fig. 5 shows the proposed FLC along with SMES unit. The $\Delta \mathrm{f}$ and $\Delta \mathrm{V}_{\mathrm{L}}$ are the inputs to the corresponding fuzzy controllers. The output of the Fuzzy Frequency Controller (FFC) is $P_{\text {dem }}$, while $Q_{\text {dem }}$ is the output of the Fuzzy Voltage Controller (FVC). At any instant, the P-Q modulation of the SMES unit depends on the present value of inductor current, $\mathrm{I}_{\mathrm{sm}}$. The P-Q regulator decides the actual value of $\left(\mathrm{P}_{\mathrm{sm}}, \mathrm{Q}_{\mathrm{sm}}\right)$ to be provided by SMES, and $\mathrm{Q}_{\mathrm{c}}$ by switched capacitor bank. Once $P_{s m}$ and $Q_{s m}$ are selected, the firing angles of the 12-pulse converter can be calculated. Fig. 6. shows the conceptual diagram of active and reactive power control of SMES unit under equal- $\alpha$ mode.

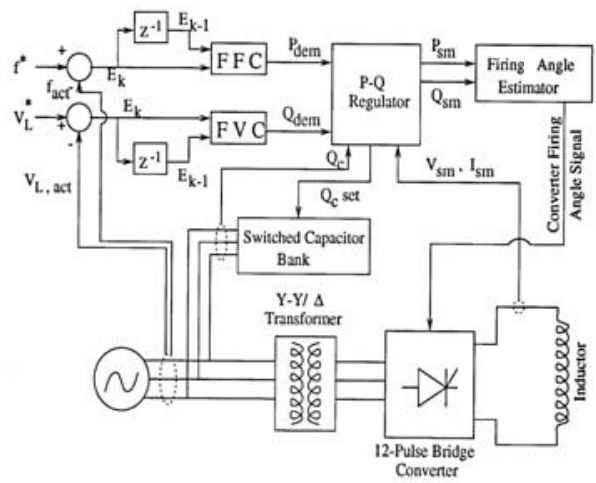

Fig. 5. Fuzzy controller for the SMES unit

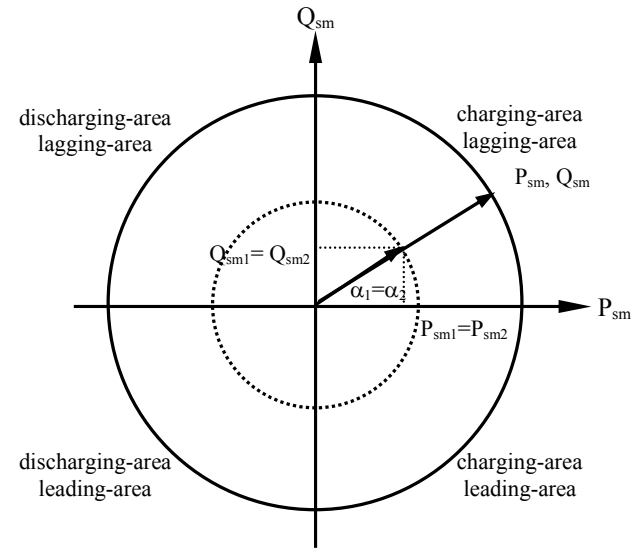

Fig. 6. Conceptual diagram of active and reactive power control of SMES unit under equal- $\alpha$ mode

\subsection{Fuzzification}

Fig. 7 shows the fuzzy logic control system with a fuzzy logic controller. The approach taken here is to exploit fuzzy rules and reasoning to generate controller parameters. The triangular membership functions for the proposed FFC of the three variables $\left(\mathrm{e}_{\mathrm{k}}, \mathrm{c} \dot{\mathrm{e}}_{\mathrm{k}}\right.$, $\left.P_{d e m}\right)$ are shown in Fig. 7, where frequency error $\left(\mathrm{e}_{\mathrm{k}}\right)$ and the rate of change of frequency error $\left(\dot{c}_{\mathrm{k}}\right)$ as shown bellow are used as the inputs of the FFC. $P_{\text {dem }}$ is the output of FFC.

Input 1: $\quad$ error $=e_{k}=\Delta f=f_{\text {norm }}-f_{t}$

Input 2: rate of change of error $=\dot{e}_{\mathrm{k}}=\dot{\Delta} \mathrm{f}=\dot{\mathrm{f}}_{\text {nominal }} \dot{\mathrm{f}}_{\mathrm{t}}$

Finally, the input variables can be expressed as per unit quantities as follows:

$\mathrm{e}_{\mathrm{k}}(\mathrm{pu})=\mathrm{e}_{\mathrm{k}}(\mathrm{k}) / \mathrm{GE}$, and $\mathrm{e}_{\mathrm{k}}(\mathrm{pu})=\mathrm{ce}_{\mathrm{k}}(\mathrm{k}) / \mathrm{GCE}$ where, $\mathrm{k}=$ Sampling interval, GE and GCE are the respective gain factors of the controllers. Considering these two inputs, the output of $\mathrm{P}_{\mathrm{dem}}$ is determined. The use of two input and single output variable makes the design of the controller very straightforward. In the triangular membership functions as shown in Fig. 7, in which linguistic variables NB, NS, Z, PS and PB stands for Negative Big, Negative Small, Zero, Positive Small and Positive Big respectively. A membership value for the various linguistic variables is calculated by the rule given by

$\mu\left(\mathrm{e}_{\mathrm{k}}, \dot{\mathrm{e}}_{\mathrm{k}}\right)=\min \left[\mu\left(\mathrm{e}_{\mathrm{k}}\right), \mu\left(\mathrm{c}_{\mathrm{k}}\right)\right]$ 
(i)

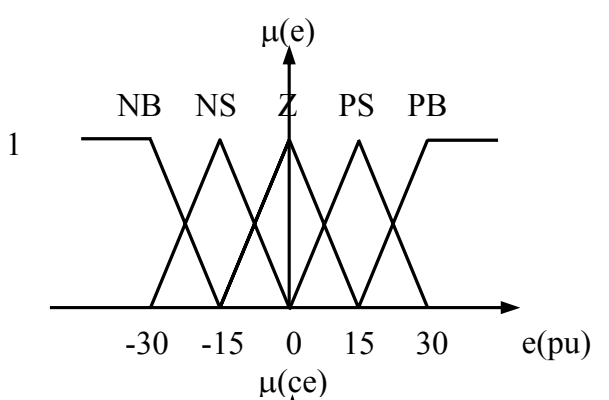

(ii)

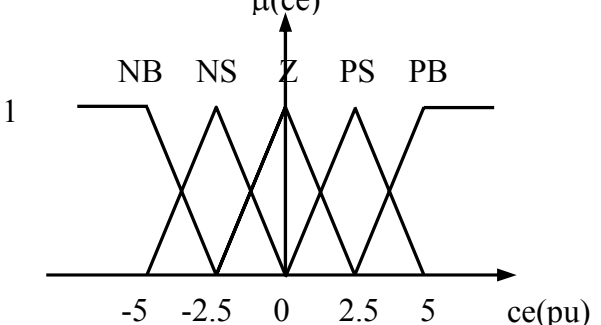

(iii)

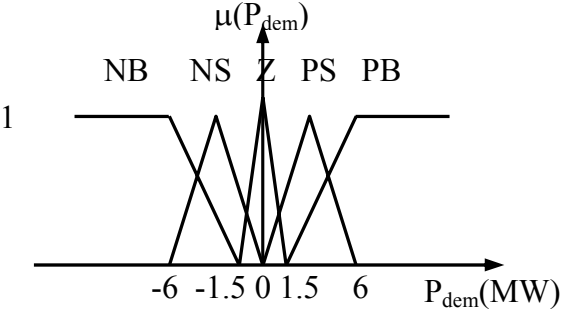

Fig. 7. Membership functions of the fuzzy frequency controller

(i) Error (ii) Change in error, and (iii) Output of the FFC

\subsection{Fuzzy Rule Base}

A fuzzy controller typically follows the "IFTHEN" rules. In the work, we have developed 25 simple control rules corresponding to 5 linguistic variables NB, NS, Z, PS and PB of the frequency deviation, for the fuzzy controller design. These are as follows:

IF $<e(k)$ is $Z>A N D<\dot{e}_{k}(k)$ is NB> THEN $u(k)$ is $P S$.

Here $u(k)$ is either $P_{\text {dem }}(M W)$ or $Q_{\text {dem }}(M V A r)$, and $\mathrm{k}$ is sampling interval.

These rules are developed easily from the viewpoint of practical system operation and by trial and error method.

\subsection{Inference Mechanism}

For the inference mechanism of the proposed fuzzy logic controller, Mamdani's method [15] has been utilized. According to Mamdani, the equation of the triangular membership function used to determine the grade of membership values in this work is as follows:

$A(x)=\frac{(b-2|x-a|)}{b}$

where $A(x)$ is the value of grade of membership, ' $b$ ' is the width and ' $a$ ' is the coordinate of the point at which the grade of membership is 1 and $x$ is the value of the input variables. The control rules for the proposed strategy are very straightforward and have been developed from the viewpoint of practical system operation and by trial and error methods. The fuzzy rule base for the fuzzy frequency controller is shown in Table 1.

Table 1: Fuzzy Rule Base for FFC

\begin{tabular}{|c|c|c|c|c|c|}
\hline $\begin{array}{c}\text { e e } \\
\text { e }\end{array}$ & NB & NS & Z & PS & PB \\
\hline NB & PB & PB & PS & PS & Z \\
\hline NS & PB & PS & PS & Z & NS \\
\hline Z & PB & PS & Z & NS & NS \\
\hline PS & PS & Z & NS & NS & NB \\
\hline PB & Z & NS & NS & NB & NB \\
\hline
\end{tabular}

\subsection{Defuzzification}

The center-of-gravity method is the most well known and rather simple defuzzification method [15], which is implemented to determine the output $\left(\mathrm{P}_{\mathrm{dem}}\right)$. This is given by the following expression

$$
P_{d e m}=\frac{\sum_{j=1}^{n} \mu_{j}{ }^{u} j}{\sum_{j=1}^{n} \mu_{j}}
$$

where $u_{j}$ is the output $\left(P_{d e m}\right)$ crispy value in the fuzzy rule table. Note that the fuzzy subsets for output variable have an asymmetrical shape causing more crowding near the origin. This allows precision control near the steady state operating point.

The control of the voltage loop is done in the same way except that the triangular membership functions and the gain factors are different.

\section{Results of the Proposed P-Q Control}

The single area power system shown in Fig. 1 is considered as a test network. The purpose is 
to highlight the behavior of SMES under fuzzy logic control scheme and its economical advantage over the conventional scheme. The degree of impact on the power system would depend on the type of the power system and the nature of the load. The section begins with system modeling followed by the simulation results and performance evaluation. Finally, economic aspects are presented. The parameters are given in Appendix-I. The following aspects are discussed in details in the sub-sections:

a) system behavior without SMES unit

b) its performance with conventional and fuzzy controller.

\subsection{System Modeling}

The following assumptions are made in the system modeling:

(i) The reheat turbine type thermal plant supplies to a single generator whose capacity is $2000 \mathrm{MW}$.

(ii) The generator is equipped with automatic voltage regulator (AVR) with stabilizing speed feedback.

(iii) The generator is cylindrical rotor type and the resistances of the generator and the line are negligible in comparison with the reactances.

(iv) Strong coupling is present between P-f and $\mathrm{Q}-\mathrm{V}$ loops. The coupling effect can be shown as follows.

In general, the active and reactive powers taken by the load are functions of frequency and voltage. Hence,

$$
\begin{aligned}
& \Delta \mathrm{P} \approx\left(\frac{\partial \mathrm{P}}{\partial \mathrm{f}}\right) \Delta \mathrm{f}+\left(\frac{\partial \mathrm{P}}{\partial|\mathrm{V}|}\right) \Delta|\mathrm{V}| \\
& \Delta \mathrm{Q} \approx\left(\frac{\partial \mathrm{Q}}{\partial \mathrm{f}}\right) \Delta \mathrm{f}+\left(\frac{\partial \mathrm{Q}}{\partial|\mathrm{V}|}\right) \Delta|\mathrm{V}|
\end{aligned}
$$

where, $\Delta \mathrm{P}$ and $\Delta \mathrm{Q}$ are the changes in the real and reactive loads as caused by relatively small variations $\Delta \mathrm{f}$ and $\Delta|\mathrm{V}|$ in frequency and voltage.

Let the step load change causing the disturbance be $\left(\Delta \mathrm{P}_{\mathrm{L}}+\Delta \mathrm{Q}_{\mathrm{L}}\right)$. The consequent changes in frequency and voltage, $\Delta \mathrm{f}$ and $\Delta \mathrm{V}_{\mathrm{L}}$, would in turn affect the loading. Therefore, the net change in real and reactive loading $\Delta \mathrm{P}_{\mathrm{LN}}$ and $\mathrm{Q}_{\mathrm{LN}}$ can be expressed as

$$
\begin{aligned}
& \Delta \mathrm{P}_{\mathrm{LN}} \approx \Delta \mathrm{P}_{\mathrm{L}}+\left(\frac{\partial \mathrm{P}_{\mathrm{L}}}{\partial \mathrm{f}}\right) \Delta \mathrm{f}+\left(\frac{\partial \mathrm{P}_{\mathrm{L}}}{\partial\left|\mathrm{V}_{\mathrm{L}}\right|}\right) \Delta\left|\mathrm{V}_{\mathrm{L}}\right| \\
& \mathrm{Q}_{\mathrm{LN}} \approx \Delta \mathrm{Q}_{\mathrm{L}}+\left(\frac{\partial \mathrm{Q}_{\mathrm{L}}}{\partial \mathrm{f}}\right) \Delta \mathrm{f}+\left(\frac{\partial \mathrm{Q}_{\mathrm{L}}}{\partial\left|\mathrm{V}_{\mathrm{L}}\right|}\right) \Delta\left|\mathrm{V}_{\mathrm{L}}\right|
\end{aligned}
$$

The net incremental power $\Delta \mathrm{P}_{\mathrm{t}}$ out of the synchronous machine is given by the sum of $\Delta \mathrm{P}_{\mathrm{G}}$ (the incremental generator power due to governor action) and $-\frac{2 \mathrm{H}}{\mathrm{f}^{0}} \frac{\mathrm{d}}{\mathrm{dt}} \Delta \mathrm{f}$ (the power derived out of the inertia of the rotor through speed change). Hence

$\Delta \mathrm{P}_{\mathrm{t}}=\Delta \mathrm{P}_{\mathrm{G}}-\frac{2 \mathrm{H}}{\mathrm{f}^{0}} \frac{\mathrm{d}}{\mathrm{dt}} \Delta \mathrm{f}$

With the addition of SMES unit at the load end, the active and reactive powers balance at the generator bus can be expressed as

$\Delta \mathrm{P}_{\mathrm{t}}=\Delta \mathrm{P}_{\mathrm{LN}}+\Delta \mathrm{P}_{\mathrm{sm}}$

$\Delta \mathrm{Q}_{\mathrm{t}}==\Delta \mathrm{Q}_{\mathrm{LN}}+\Delta \mathrm{Q}_{\mathrm{sm}}$

Using equations (14), and (15), the following is obtained:

$$
\begin{aligned}
\Delta \mathrm{P}_{\mathrm{G}}-\frac{2 \mathrm{H}}{\mathrm{f}} \frac{\mathrm{d}}{\mathrm{dt}} \Delta \mathrm{f}= & \Delta \mathrm{P}_{\mathrm{L}}+\left(\frac{\delta \mathrm{P}_{\mathrm{L}}}{\delta \mathrm{f}}\right) \Delta \mathrm{f}^{+}\left(\frac{\delta \mathrm{P}_{\mathrm{L}}}{\delta\left|\mathrm{V}_{\mathrm{L}}\right|}\right) \Delta\left|\mathrm{V}_{\mathrm{L}}\right| \\
& +\Delta \mathrm{P}_{\mathrm{Sm}}
\end{aligned}
$$

or,

$$
\frac{\mathrm{d}}{\mathrm{dt}} \Delta \mathrm{f}=\frac{\mathrm{f}^{0}}{2 \mathrm{H}}\left[\Delta \mathrm{P}_{\mathrm{G}}-\Delta \mathrm{P}_{\mathrm{L}}-\left(\frac{\delta \mathrm{P}_{\mathrm{L}}}{\delta \mathrm{f}}\right) \Delta \mathrm{f}-\left(\frac{\delta \mathrm{P}_{\mathrm{L}}}{\delta\left|\mathrm{V}_{\mathrm{L}}\right|}\right) \Delta\left|\mathrm{V}_{\mathrm{L}}\right|-\Delta \mathrm{P}_{\mathrm{Sm}}\right]
$$

\section{Simulation Results}

\subsection{Results without SMES}

Non-linear dynamic equations are used in the solution process. They are solved using 4th order R-K method. The time step and simulation have been chosen as $0.0015 \mathrm{sec}$ and $15 \mathrm{sec}$ respectively. Two case-studies were conducted on the system: Case-1 corresponding to sudden load change of $(0.005$ $+\mathrm{j} 0.005) \mathrm{pu}$ and Case-2 corresponding to sudden load change of $(0.008+\mathrm{j} .0 .008)$ pu.

The frequency, rotor angle deviation, load voltage deviations and terminal voltage deviations of the power system without SMES unit for the above two cases are shown in Fig. 
8. In Case-1, the maximum frequency and load-voltage deviations are $-0.0156 \mathrm{~Hz}$ and $0.00306 \mathrm{pu}$ respectively. The maximum frequency and load-voltage deviations in the Case-2 are - $0.025 \mathrm{~Hz}$ and $0.00528 \mathrm{pu}$ respectively. The rotor angle also deviates accordingly for both the cases. The maximum terminal voltage deviation for Case- 1 and Case- 2 are $-0.004 \mathrm{pu}$ and $-0.0084 \mathrm{pu}$ respectively. The coupling effect between the $\mathrm{Q}-\mathrm{V}$ and P-f loops is the main cause for the oscillations.

\subsection{Performance Evaluation with SMES}

\section{Case-1: Load change $(0.005+j 0.005) \mathrm{pu}$}

Fig. 9 shows the simulation results for this case. When conventional controller is used, the maximum frequency deviation is $0.0105 \mathrm{~Hz}$, and this occurs at an expense of change in the inductor current of $-1.5 \mathrm{kA}$. Meanwhile, the fuzzy controller limits the frequency deviation to $0.0093 \mathrm{~Hz}$ at the expense of inductor current change of $-1.48 \mathrm{kA}$. It is evident from Fig. 9 that the fuzzy controller can provide better compensation with less deviation of inductor current. This ensures the effective use of its power modulation. There is not much gain in voltage control loop except that the reactive power compensation provided by fuzzy controller is less than the conventional one for the similar load voltage profiles. Terminal voltage responses also show better performance with the effective use of proposed fuzzy logic controllers.

\section{Case-2: Load change of $(0.008+j 0.008) \mathrm{pu}$}

Fig. 10 shows the results for this case. Compared to the results of Case-1, the fuzzy controller shows significant development for the larger disturbance. Fig. 10 shows that the P-modulation by the SMES unit with fuzzy controller reduces the frequency oscillation by almost $24.3 \%$ compared with $18.9 \%$ reduction by the conventional controller. Significant improvements in the first overshoot and settling time are also clearly observed. The inductor current deviation is much less than that of conventional controller. Like the previous case, the effective use of active and reactive power modulation is also ensured.

In the case of sudden load application, system frequency goes down quickly in the first half cycle, so compensation provided by the SMES unit $\left(\mathrm{P}_{\mathrm{sm}}\right)$ just after detecting the disturbance is very important. The FFC chooses the initial value of $\mathrm{P}_{\mathrm{sm}}$, depending on the frequency deviations and rate of change of frequency deviations. The change in $\Delta \mathrm{f}$ is considered as a dominant factor in the first cycle. Fig. 9 and 10 show that fuzzy controller is able to damp the frequency oscillations by providing suitable compensation. Notice that there is a considerable increase in $\mathrm{P}_{\mathrm{sm}}$ just after disturbance. This in turn results in a smaller frequency deviation, which eventually leads to a smaller $\Delta \mathrm{I}_{\mathrm{sm}}$ and a faster restoration of system frequency. With the help of switched capacitor bank, the $\mathrm{Q}_{\text {net }}$ supplied by SMES unit substantially reduces the voltage deviation.

Similarly, during the initial period immediately after the sudden increase in load, the slope of the voltage deviation is very large and negative. The negative voltage deviation requires capacitive Var and initial values of $\mathrm{Q}_{\mathrm{dem}}$ are accordingly chosen by FVC after satisfying the requirement of $\mathrm{P}_{\mathrm{sm}}$. Like FFC, the $\mathrm{FVC}$ also considers the change in $\Delta \mathrm{V}_{\mathrm{L}}$ as a dominant factor in the first cycle. It is seen that with less Var compensation, the FVC is able to maintain same voltage deviation like the conventional controller.

In both these cases, the $\mathrm{P}$ - modulation by the SMES unit reduces the oscillation in the frequency while Q-modulation along with the reactive power provided by the switched capacitor bank improves the load voltage profiles. However, Fig. 9-10 clearly show the advantage of fuzzy logic controller over conventional controller in every aspect. 

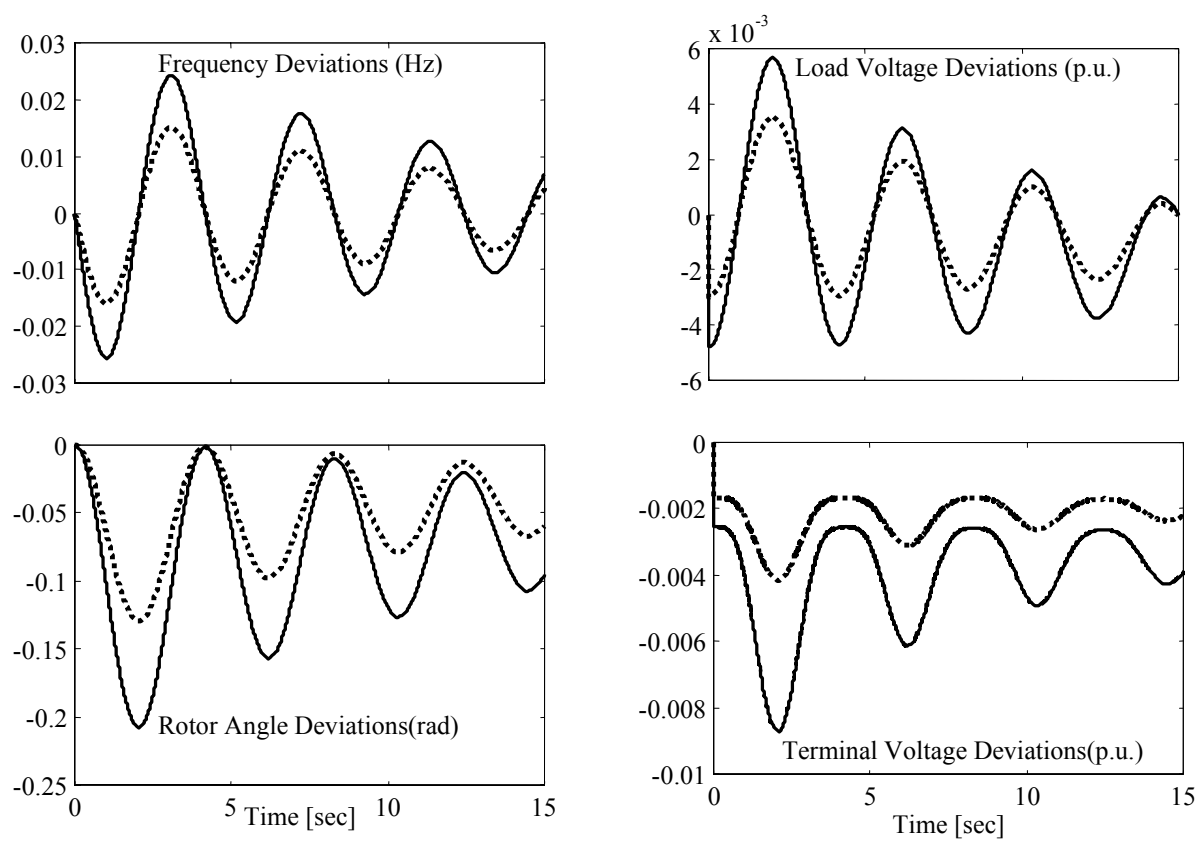

Fig. 8. Responses of the power system without SMES Unit [Case-1]........ and [Case-2]
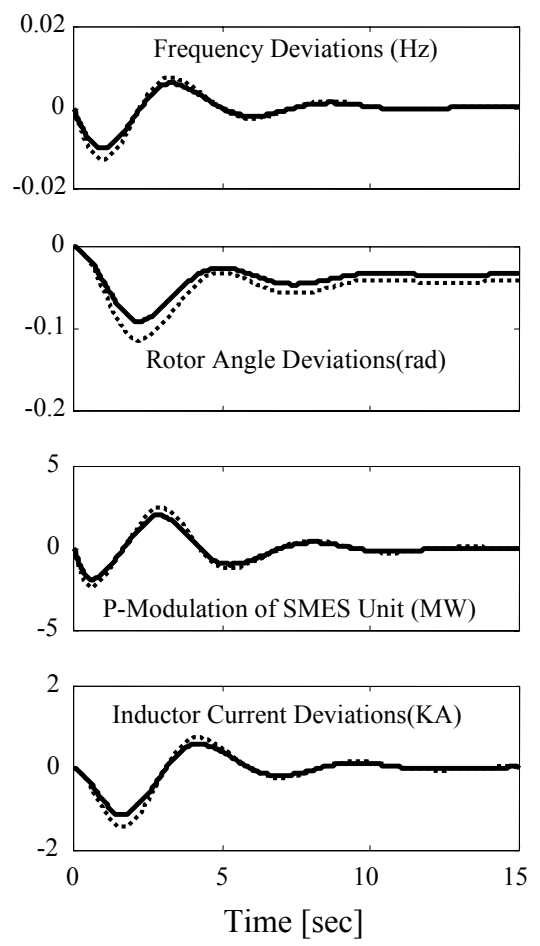
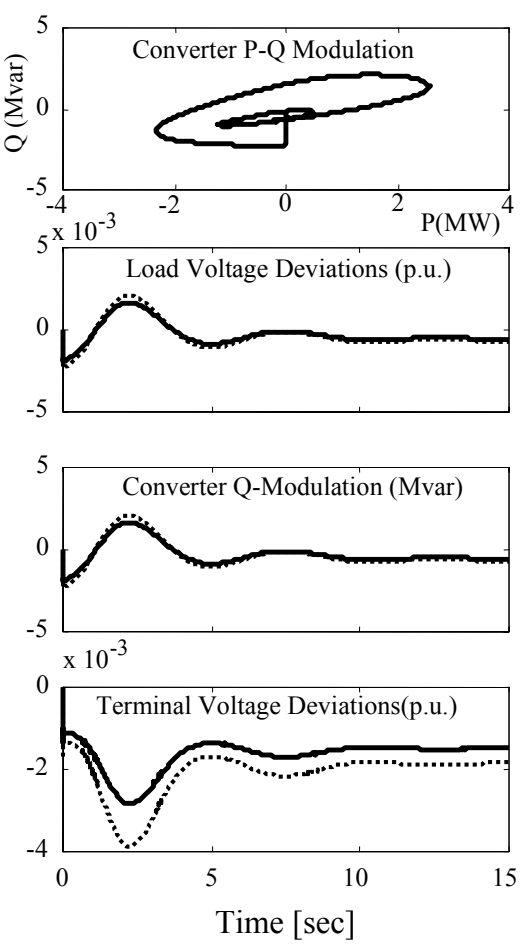

Fig. 9. Responses of the power system after addition of SMES unit using fuzzy logic control [Case-1] Conventional 

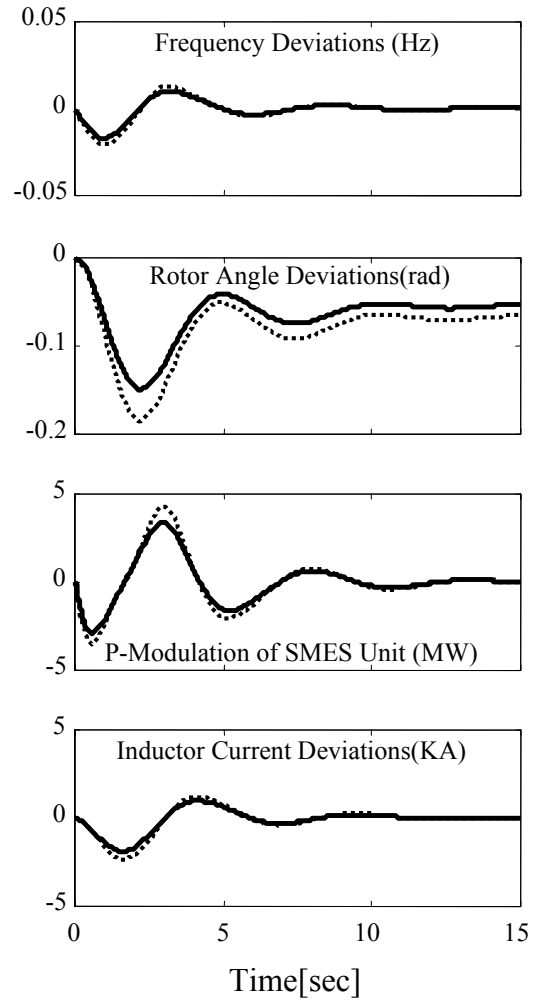
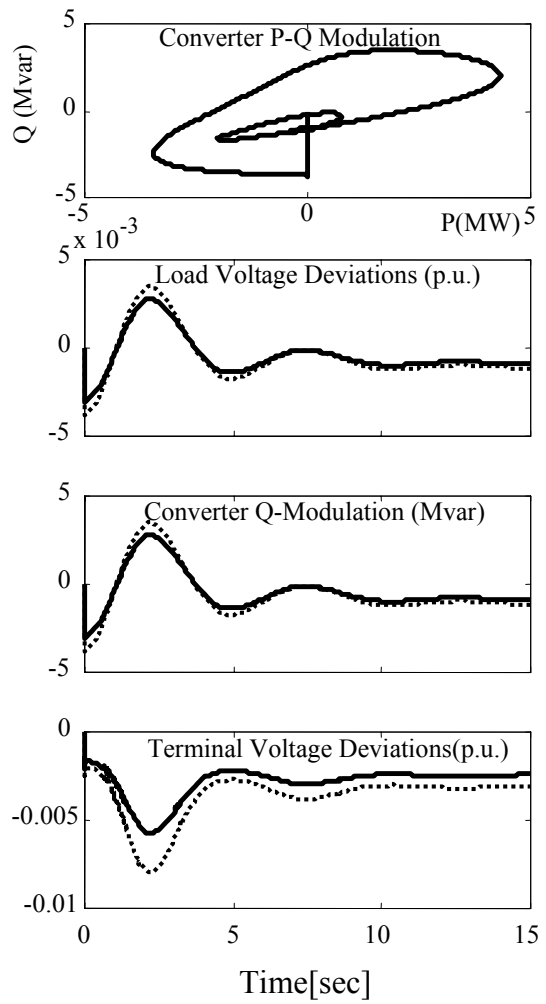

Fig. 10. Responses of the power system after addition of SMES unit using fuzzy logic control [Case-2] Conventional Fuzzy

\section{Economic Aspect}

One of the most important criteria of using SMES unit either for load leveling and/or the improvement of power system performance is that it should be economically viable. With the proposed mode of control the fluctuation of inductor current is smaller. This clearly indicates that the SMES unit with fuzzy logic control is able to handle much bigger disturbances within the same capacity as compared with other controllers. Fig. 10 shows that the rating of switched capacitor bank can be decreased with the proposed mode of control, which further decreases the cost of the SMES unit.

\section{Conclusion}

This paper presents a new method of controlling the SMES unit for improving the dynamic performance of the single area power system. Fuzzy logic was used to design frequency and voltage controllers to generate required control signals for the SMES unit. Direct generation of control signals for the 12pulse converter from active and reactive power modulation using both error signals and change in successive error signals, makes the proposed controller more sensitive. As a result, in the proposed FLC system the time taken to damp the system oscillations is comparatively smaller. Also this occurs with a smaller deviation of the inductor current. Thus the size of the SMES unit can be reduced and the rating of the switched capacitor bank can be made smaller.

\section{References}

[1] P.M. Anderson and A. A. Fouad, Power System Control and Stability, Iowa State University press, Ames, Iowa, 1977.

[2] M.R.I. Sheikh, M.G. Rabbani and M.M. Ali,'Superconducting Magnetic Energy Storage Unit for Power System Application', $2^{\text {nd }}$ International Conference on Electrical Engineering (ICEE-2002), October 23-24, 2002, pp.124-130.

[3] I. Ngamroo, S. Dechanupaprittha, K. Hongesombut, Y. Mitani and A. Kunakorn "Design of Robust 
Load-Frequency Stabilizers of SMES in Coordination with SSSC", Proceedings of International Power Engineering Conference (IPEC2005), CD-ROM, December, 2005.

[4] S. Dechanupaprittha, K. Hongesombut, M. Watanabe, Y. Mitani and I. Ngamroo " A Heuristicbased Design of Robust SMES Controller Taking System Uncertainties into Consideration", Transactions on Electrical and Electronic Engineering (IEEJ), Vol. 1, pp. 255-267, 2006.

[5] A. Demiroren, H. L. Zeynelgil and S. N. Sengor "The Application of Neural Network Controller to Power System with SMES for Transient Stability Enhancement" European Transactions on Electrical Power, Vol. 16, pp.629-646, July 2006.

[6] Demiroren A, Zeynelgil HL "The Transient Stability Enhancement of Synchronous Machine with SMES by Using Adaptive Control", Electric Power Components and Systems, 2002; 30(3):233249.

[7] K. Hongesomebut, Y. Mitani, and K. Tsuji, "An Adaptive Static Var Compensator Using Genetic Algorithm and Radial Basis Function Network for Enhancing Power System Stability", Proceedings of the IEEE Porto Power Tech Conference in Porto, Portugal, September 2001.

[8] Molina, M.G. and P. E. Mercado, "New Energy Storage Devices for Applications on Frequency Control of the Power System using FACTS Controllers", Proc. X ERLAC, Iguazú, Argentina, 14.6, 1-6 (2003)

[9] H. J. Boening and J. F. Hauer, Commissioning test of the bonneville 30 MJ super-conductive magnetic energy storage unit, IEEE Trans. on Power Appar. Syst., PAS - 104 (1985).

[10] Y. Mitani , K. Tsuji, and Y. Murakami , Application of superconducting magnetic energy storage to improve power system dynamic performance, IEEE Trans. Power Syst., 3(1988), 1418-1425.

[11] IEEE Task Force on Benchmark Models for Digital Simulation of FACTS and Custom-Power Controllers, T\&D Committee, "Detailed Modeling of Superconducting Magnetic Energy Storage (SMES) System," IEEE Trans. on Power Delivery, Vol. 21, No. 2, pp. 699-710, April 2006.

[12] Mairaj uddin Mufti, Shameem Ahmad Lone, Sheikh Javed Iqbal, Imran Mushtaq "Improved Load Frequency Control with Superconducting Magnetic
Energy Storage in Interconnected Power System", IEEJ Trans. 2007, vol. 2,pp. 387-397.

[13] K. Rasool, and S. Alireza, Fuzzy power flow analysis, Electr. Power Syst. Res., 29 (1994), 105 . 109.

[14] Ali MH, Murata T, Tamura J. "Fuzzy Logic Controlled SMES for Damping Shaft Torsional Oscillations of Synchronous Generator", Transactions on Electrical and Electronics Engineering, 2006; 1(1): 116-120.

[15] D. Driankov, H. Hellendoorn, and M. Reinfrank: An Introduction to Fuzzy Control, Springer-Verlag (1993).

\section{Appendix - I}

System Parameters:

Area capacity $\mathrm{P}_{\mathrm{R}}=2000 \mathrm{MW}$, Base MVA=2000.

Nominal loading $=1000 \mathrm{MW}$ at 0.9 p.f. lagging.

Nominal load-end voltage $=1.0 \angle 0^{0}$ p.u.

$\mathrm{f}^{0}=50 \mathrm{~Hz}, \mathrm{X}_{\mathrm{d}}=1.0 \mathrm{pu}, \mathrm{X}_{\mathrm{d}}{ }^{\prime}=0.25 \mathrm{pu}, \mathrm{X}_{\mathrm{t}}=0.3 \mathrm{pu}, \quad \mathrm{H}$

$=5.0 \mathrm{~s}, \mathrm{R}=2.4 \mathrm{~Hz} / \mathrm{pu} \mathrm{MW}, \mathrm{K}_{\mathrm{p}}=100.0 \mathrm{~Hz} / \mathrm{pu} \mathrm{MW}, \mathrm{K}_{\mathrm{r}}$ $=0.5, \mathrm{~T}_{\mathrm{p}}=20.0 \mathrm{~s}, \mathrm{~K}_{\mathrm{r}}=0.5, \mathrm{~T}_{\mathrm{p}}=20.0 \mathrm{~s}, \mathrm{~T}_{\mathrm{T}}=0.3 \mathrm{~s}, \mathrm{~T}_{\mathrm{G}}=$ $0.08 \mathrm{~s}, \mathrm{~T}_{\mathrm{r}}=10.0 \mathrm{~s}$, and $\mathrm{K}_{\mathrm{I}}=0.8$.

FFC: $\mathrm{GE}=10^{-3}, \mathrm{GCE}=10^{-5}$

FVC: $\mathrm{GE}=10^{-3}, \mathrm{GCE}=10^{-6}$

SMES:

$\mathrm{S}_{\max }=9.6 \mathrm{MVA}, \mathrm{L}=0.5 \mathrm{H}, \mathrm{I}_{\mathrm{d} 0}=4.0 \mathrm{kA}, \mathrm{R}_{\mathrm{L}}=0.0, \mathrm{~V}_{\mathrm{d} 0}$

$=1.2 \mathrm{kV}$, and $\mathrm{R}_{\mathrm{C}}=0.02 \Omega$

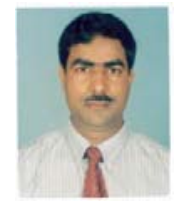

M.R.I. Sheikh was born in Sirajgonj, Bangladesh on October 31, 1967. He received his B.Sc. Engineering and M.Sc. Engineeering Degree from Rajshahi University of Engineering \& Technology (RUET), Bangladesh, in 1992 and 2003 respectively, all in Electrical and Electronic Engineering. He carryout his Ph.D degree from Kitami Institute of Technology, Hokkaido, Kitami, Japan in 2010 in the field of Renewable Wind Energy. He is currently an Associate Professor in the Electrical and Electronic Engineering Department, RUET. His research interests are, Power system stability enhancement including wind generator by using SMES, FACTs devices and Load Frequency Control of multi-area power system.

Mr. Sheikh is the member of the IEB and the BCS of Bangladesh. 